\title{
O projeto da Associação dos Arquivistas Brasileiros para o campo arquivístico
}

Eliezer Pires da Silva

Doutor em Memória Social. Docente Adjunto da
UNIRIO, no Programa de Pós-Graduação em
Gestão de Documentos e Arquivos
(UNIRIO/PPGARQ)

Evelyn Goyannes Dill Orrico

Doutora em Ciência da Informação IBICT-UFRJ.
Docente Associada da UNIRIO, no Programa de
Pós-Graduação em Memória Social
(UNIRIO/PPGMS)

http://dx.doi.org/10.1590/1981-5344/1916

Este artigo busca compreender o surgimento do modelo nacional de institucionalização do campo arquivístico, formulado pela Associação dos Arquivistas Brasileiros durante a década de 1970, configurando um quadro corporativista evidenciado pelas conquistas desse associativismo na relação com o Estado brasileiro. Objetiva especificamente analisar o discurso do associativismo arquivístico sobre a institucionalização das esferas acadêmico-universitária do saber arquivístico e sua reserva de mercado profissional. A abordagem metodológica foi utilizar os editoriais da revista Arquivo \& Administração, entre 1971 e 1978, selecionando enunciações sobre o processo de institucionalização do campo arquivístico. As análises apontam para uma década de incessantes esforços para eliminar, do campo profissional, o livre exercício da ocupação, para fortalecer o âmbito da formação. Associado à seleção dos enunciados significativos, depreendeu-se a rede de pessoas interessadas nos arquivos, em condições históricas de restrição política, que construiu articulações frente ao Estado, diante de pontos de vista contrários, se tornando um movimento associativo realizador em suas demandas.

Palavras-chaves: Campo arquivístico; Arquivista; Arquivologia; Memória Social; Memória e linguagem; Análise do discurso. 


\section{The project for Archival Science designed by the Association of Brazilian Archivists}

This article seeks to understand the emergence of the national model of institutionalization of archival science, devised by the Association of Brazilian Archivists during the 1970s, which set up a corporatist framework, evidenced by the achievements of this associative movement in its relationship with the Brazilian government. It specifically aims to analyze the discourse of the archival associative movement about the institutionalization of the academic spheres of archival science and its niche in the labor market. The methodological approach was to use the editorials of the journal Archive \& Administration, between1971 and 1978, and select relevant utterances about the process of institutionalization of the archival field. The analysis points to a decade of tireless efforts to eliminate the free exercise of the profession in order to focus on the education and training of archivists. Together with the selection of relevant utterances, analysis was done of the network of people interested in archives, during a period of political repression, who established liaisons with the government when they had to face opposite viewpoints, thus enabling the associative movement to be successful in its demands.

Keywords: The Archival field; Archivist; Archival Science; Social Memory; Memory and language; Discourse analysis

Recebido em 14.12.2014 Aceito em 23.08.2015

\section{Introdução}

O associativismo dos arquivistas no Brasil na década de 1970 comportou um trabalho de memória inscrito no próprio discurso desse coletivo, que permite conhecer o projeto que modelou a institucionalização do campo arquivístico no país. Tal instância de ação coletiva participou efetivamente da formalização no Brasil dos sentidos para os termos Arquivologia como formação específica de nível universitário e arquivista como ocupação exclusiva aos egressos daquela graduação (SILVA; ORRICO, 2012). 
Paul Ricouer foi um filósofo que participou de debates sobre memória e articulou a sua relação com a linguagem. O autor demonstra uma arte de memória, que não é imaginação, pensada desde a filosofia antiga. A memória é, sobretudo, uma capacidade de (re) significar as coisas e a si e não apenas um instrumento de guardar dados mnemônicos. Desse modo, as lembranças e os esquecimentos dos agentes e das testemunhas da institucionalização do campo arquivístico é parte constitutiva do processo sócio-histórico ou da trajetória de formação da arquivologia e do arquivista no Brasil posta em questão nesta pesquisa.

É no quadro de um pensamento coletivo que se realizaria o ato pessoal de recordação socialmente marcado pelo lugar ocupado e as relações mantidas e alteradas nesse contexto. Nesse ponto, a argumentação de Ricouer (2007) encontra-se entre uma sociologia da memória coletiva e uma fenomenologia da memória individual, considerando tanto a possibilidade de consciência do eu individual quanto a capacidade de entidades coletivas de recordar e manter lembranças compartilhadas.

A argumentação de Ricouer sobre as operações constitutivas da memória relaciona o enigma da representação presente de uma coisa ausente marcada pelo selo da anterioridade com a pertinência dos discursos de memória para elucidar o trabalho de lembrança e esquecimento sobre a institucionalização com campo arquivístico no Brasil na década de 1970. Busca-se na região da linguagem uma instância declarativa da memória, "a lembrança é dita, pronunciada, já é uma espécie de discurso que o sujeito trava consigo mesmo." (RICOUER, 2007, p. 138) Essa condição declarativa da memória também seria o seu ingresso na esfera pública, de impedimentos, manipulações, fragilidades no confronto com o plano institucional.

Portanto, a idéia de trabalho de memória se realizaria num plano intermediário entre a memória viva das pessoas individualmente e a memória pública de comunidades a que se pertence, construída no e pelo discurso.

O veículo desses discursos em questão, a revista Arquivo \& Administração, esteve entre as primeiras iniciativas de organização do movimento dos arquivistas quando fundou a Associação dos Arquivistas Brasileiros em 1971. A criação deste instrumento de divulgação, na perspectiva do fenômeno associativo, equivale a instrumento de ação, por isso, em relação à revista "os objetivos que determinam a sua existência são os mesmos da Associação dos Arquivistas Brasileiros, da qual é o órgão de divulgação" (ASSOCIAÇÃO DOS ARQUIVISTAS BRASILEIROS, 1972, p. 2).

Trabalhamos com o seguinte questionamento: se a institucionalização da Arquivologia e do arquivista foram demandas formuladas e reivindicadas pelo movimento associativo dessa área, a questão está em saber qual era o seu projeto para o campo. Além disso, problematizar se seria o coletivo de profissionais que se ocupavam com arquivos, liderados pelos mais engajados, buscando transformar uma precária realidade dos arquivos, ou se seria a emergência do 
corporativismo vislumbrando a oportunidade de instituir sua lógica de reprodução da área além de reservar seu mercado.

Hoje podemos identificar trabalhos que exploram de algum modo o percurso de constituição do campo arquivístico no Brasil. Cláudio Dutra Crespo (2000), Maria Odila Fonseca (2004), Augusto Moreno Maia (2006), Angélica Alves da Cunha Marques (2007; 2011), Paulo Roberto Elian dos Santos (2008), Maria Leonilda Reis da Silva (2010), Katia Isabelli Melo de Souza (2011) e Yuri Queiroz Gomes (2011) realizaram pesquisas em programas de pós-graduação e procuraram explicações sobre a trajetória acadêmico-institucional e profissional do campo arquivístico no país.

Os trabalhos analisados diferem quanto aos seus objetivos específicos de pesquisa, mas assemelham-se na procura de interpretações sobre a trajetória da área arquivística no Brasil. Os posicionamentos vão desde uma origem identificada na criação do Arquivo Nacional, em 1838; nas duas iniciativas da instituição, de 1911 e 1960, dos cursos de diplomática e depois de arquivo; no papel do Departamento Administrativo do Serviço Público (DASP) e da Fundação Getúlio Vargas (FGV) na modernização do Estado; no movimento associativo da década de 1970; no projeto de modernização do Arquivo Nacional nos anos de 1980; e até na configuração do campo a partir de 1991 com os cursos universitários e as leis da profissão e dos arquivos, respectivamente.

Compartilhamos do posicionamento que reconhece realizações do movimento associativo, na década de 1970, sobre o modelo nacional de institucionalização da arquivologia (curso universitário) e do arquivista (profissão legalmente de quem cursou essa graduação). Consideramos os avanços desses estudos anteriores, contudo, dentro da perspectiva discursiva, somos originais ao investigarmos sobre como a institucionalização do campo arquivístico (expressa por sua inserção acadêmico-universitária e sua regulamentação profissional) está vinculada ao associativismo instituído pelas ações da Associação dos Arquivistas Brasileiros, em 1971.

\section{0 modelo de institucionalização do campo arquivístico}

O discurso da Associação dos Arquivistas Brasileiros na década de 1970 nem sempre foi o discurso de propostas para os problemas dos arquivos. Embora considerasse tal aspecto, há recorrente ênfase na organização da classe com status universitário e critérios de exclusão da alteridade não tolerada. Em consequência disso, observa-se uma demanda direta ao governo para que se crie a graduação em Arquivologia bem como a regulamentação da profissão de arquivista. A Associação dos Arquivistas Brasileiros buscava uma reserva de mercado que se associava claramente ao anseio desse coletivo pelo controle estatal sobre o livre exercício do trabalho arquivístico, até então desempenhadas sem qualquer exigência de formação prévia (SILVA; ORRICO, 2012).

As complexidades do discurso do associativismo sobre como foi a institucionalização do campo arquivístico no Brasil se estendem desde a percepção, por parte do coletivo profissional, de que o movimento 
representava um marco para a atividade arquivística no país, até as tensões na relação com historiadores, museólogos, bibliotecários, Conselho Federal de Cultura e DASP sobre a realização da atividade arquivística. É importante notar o trabalho de memória no discurso da Associação dos Arquivistas Brasileiros sugerindo, apesar da variação nos termos utilizados, que o coletivo profissional dispunha de projeto para o campo arquivístico: a constituição de controles institucionais no desenvolvimento de um corpo de especialistas com formação e carreira.

O projeto de institucionalização do campo arquivístico inclui um discurso que desde logo apresenta sua retórica sobre a base material do emergente corporativismo, caracterizando uma realidade de "serviços de arquivo, encarados sem devida atenção" (ASSOCIAÇÃO DOS ARQUIVISTAS BRASILEIROS, 1972, p. 2), em que "a administração pública continua negligenciando seus documentos" (ASSOCIAÇÃO DOS ARQUIVISTAS BRASILEIROS, 1973a, p. 5), sem que haja "como explicar o desamparo, o descuramento que tem havido" (ASSOCIAÇÃO DOS ARQUIVISTAS BRASILEIROS, 1974c, p. 5), responsabilizando as "autoridades governamentais que nos seus planos pouco atribuem aos Arquivos" (ASSOCIAÇÃO DOS ARQUIVISTAS BRASILEIROS, 1975b, p. 5), a negligência imperaria a despeito do fato de que "Arquivo é matéria de infra-estrutura"(ASSOCIAÇÃO DOS ARQUIVISTAS BRASILEIROS, 1973a, p. 5).

Mas essa retórica não pode esconder que o fundamental para Associação dos Arquivistas Brasileiros é que a mesma se concebe como necessária, e seu projeto para o campo arquivístico é o status universitário e a reserva de mercado do arquivista. O modelo de institucionalização apresentava essas duas frentes. O discurso demonstra o coletivo em ação pelo seu projeto, "lutamos por finalidades duradouras em termos de técnica e de profissionalização" (ASSOCIAÇÃO DOS ARQUIVISTAS BRASILEIROS, 1976c, p. 5). Considerando a vinculação profissional da maioria que compunha esse movimento associativo, tratase da expectativa de estabelecer uma linha profissional específica de arquivistas no serviço público.

Quadro 1 - Enunciações da AAB sobre seu modelo de institucionalização do campo arquivístico, nos editoriais da revista Arquivo \& Administração, 1972-1978

\begin{tabular}{|c|c|c|}
\hline Modelo & Edição & Enunciados \\
\hline \multirow{10}{*}{$\begin{array}{l}\text { Status universitário } \\
\text { para a formação em } \\
\text { Arquivologia }\end{array}$} & 1972 & ..."cursos de arquivo em nível superior e técnico." \\
\hline & $1973 b$ & ..."arquivistas com formação de arquivistas”... \\
\hline & $1973 c$ & $\begin{array}{l}\text {... "a formação universitária propiciará profissionais } \\
\text { competentes para cuidar dos arquivos"... }\end{array}$ \\
\hline & $1974 \mathrm{a}$ & ... "a criação de curso universitário"... \\
\hline & $1974 \mathrm{a}$ & ... "formação de técnicos de nível superior"... \\
\hline & $1974 b$ & $\begin{array}{l}\text {... "formação específica dos cursos superiores de } \\
\text { arquivo"... }\end{array}$ \\
\hline & $1975 \mathrm{a}$ & ... “implantação de cursos superiores”... \\
\hline & $1975 \mathrm{a}$ & ... "formação de pessoal de nível superior"... \\
\hline & $1977 \mathrm{~b}$ & ... "mandato universitário"... \\
\hline & $1977 b$ & ... "Curso Superior de Arquivologia"... \\
\hline
\end{tabular}




\begin{tabular}{|c|c|c|}
\hline & $1975 \mathrm{c}$ & ... "criação do Curso Superior de Arquivologia"... \\
\hline & $1976 \mathrm{a}$ & $\begin{array}{l}\text {... "obter 'status' para os arquivistas, mediante criação } \\
\text { de cursos de formação"... }\end{array}$ \\
\hline \multirow{13}{*}{$\begin{array}{l}\text { Regulamentação da } \\
\text { profissão com } \\
\text { mecanismos de reserva } \\
\text { para o exercício da } \\
\text { atividade arquivística }\end{array}$} & $1975 \mathrm{a}$ & ... "regulamentação da profissão"... \\
\hline & $1975 \mathrm{a}$ & $\begin{array}{l}\text {... “regulamentação, em níveis condignos, de uma } \\
\text { profissão"... }\end{array}$ \\
\hline & $1975 b$ & ... "projeto de regulamentação da profissão"... \\
\hline & $1975 \mathrm{c}$ & ..."Regulamentação da Profissão" \\
\hline & $1977 \mathrm{a}$ & ... "a regulamentação da profissão"... \\
\hline & $1977 \mathrm{a}$ & $\begin{array}{l}\text {... "trabalho dedicado à regulamentação da } \\
\text { profissão"... }\end{array}$ \\
\hline & $1977 \mathrm{~b}$ & ..."pugnar pelo reconhecimento oficial da profissão"... \\
\hline & $1977 \mathrm{~b}$ & ... “solicitar a Regulamentação da Profíssão"... \\
\hline & $1977 \mathrm{c}$ & ... "regulamentação da nossa profissão"... \\
\hline & $1978 b$ & $\begin{array}{l}\text {... "regulamentação das profissões de arquivista e de } \\
\text { técnico de arquivo"... }\end{array}$ \\
\hline & $1978 b$ & ... "a regulamentação da nossa profissão." \\
\hline & $1978 b$ & ... "reconhecimento da nossa profissão"... \\
\hline & $1978 \mathrm{c}$ & ... "regulamentação profissional". \\
\hline
\end{tabular}

Fonte: Dados da pesquisa.

No quadro acima é possível observar quando as metas do projeto da $A A B$ são enunciadas com mais frequência: a graduação em Arquivologia (entre 1974 e 1975) e da regulamentação da profissão de arquivista (entre 1977 e 1978). As datas coincidem com eventos significativos sobre cada uma das metas: questões de operacionalização do mandato universitário concedido ao Curso Permanente de Arquivos do Arquivo Nacional pela Universidade Federal do Rio de Janeiro, durante os anos de 1974 e 1975; processo legislativo, promulgação e regulamentação da lei federal da profissão de arquivista, durante os anos de 1977 e 1978.

O que deve ser considerado, ainda, nesse quadro de análise dos discursos, ou trabalhos de memória, sobre o processo de institucionalização do campo arquivístico no Brasil é o conceito de formação discursiva, entendido como a projeção na linguagem dos sentidos das palavras e das proposições determinados por posições ideológicas regulando o que pode e deve ser dito (FOUCAULT, 2005; ORLANDI; GUIMARÃES, 2006; FERNANDES, 2008), aspecto a partir do qual se enquadra o discurso da Associação dos Arquivistas Brasileiros dentro de uma formação discursiva sintetizada pelo termo corporativa.

Outra formação discursiva sobre o campo arquivístico naquele momento era a perspectiva integradora dos profissionais dos arquivos, das bibliotecas e dos museus, representada pelo Departamento Administrativo do Serviço Público (DASP), mas que polarizava com o discurso $A A B$. As posições diferentes podem ser ilustradas no seguinte enunciado: "como medida de absoluta justiça e oportunidade aguarda que o DASP reexamine a situação imprópria que vem de instituir, ignorando a existência e importância de uma linha profissional arquivística no serviço público" (ASSOCIAÇÃO DOS ARQUIVISTAS BRASILEIROS, 1974a, p. 3).

Para além das duas formações discursivas postas em evidência nos parágrafos anteriores, é preciso considerar uma terceira que pode ser observada a partir da fundação de uma sociedade destinada a colaborar 
com arquivos públicos tendo em vista seu interesse na História. A Associação de Pesquisa Histórica e Arquivística (APHA), fundada dez meses antes da Associação dos Arquivistas Brasileiros, significa um posicionamento ideológico não identificado com o corporativismo dos arquivistas e sua proposta de modelar a formação e a carreira desse profissional é diferente.

A proposta da APHA é concorrente porque o ponto fundamental encontra-se na pretensão de extrair da "tecnologia arquivística" recursos para servir à análise e à crítica historiográfica. Há uma divisão do trabalho com documentos arquivísticos em que os historiadores são os profissionais da interpretação - "eruditos" responsáveis pela tarefa "heurística"- já os arquivistas, apenas dedicados ao adequado acondicionamento dos documentos. No discurso da APHA, "o trabalho do arquivista é um trabalho preparatório" (ARQUIVO NACIONAL, 1971a, p. 11). Essa é uma formação discursiva na qual não cabe o projeto da $A A B$ de status universitário para formar arquivistas, isso porque a ocupação do arquivista é uma simples atividade técnica.

As divergências que APHA e $A A B$ apresentam nos seus discursos podem ser notadas nos desdobramentos concretos de disputa pelo papel de representar a classe dos profissionais de arquivo, um lado afirma, "a APHA será a vossa Associação de classe" (ARQUIVO NACIONAL, 1971a, p. 7), no entanto o outro lado discorda, "caberia a AAB pugnar pelo reconhecimento oficial da profissão" (ASSOCIAÇÃO DOS ARQUIVISTAS BRASILEIROS, 1977b, p. 3).

Quadro 2 - Formações discursivas sobre o campo arquivístico no Brasil

\begin{tabular}{l|l}
\hline \multicolumn{1}{c|}{ Formação discursiva } & \multicolumn{1}{c}{ Ordem do discurso } \\
\hline \hline Corporativa & $\begin{array}{l}\text { Projeto de organização da classe contando com status acadêmico- } \\
\text { universitário para formação do arquivista, além de reserva legal desse } \\
\text { mercado. }\end{array}$ \\
\hline Integração de profissões & $\begin{array}{l}\text { Compreensão integrada da formação e do exercício profissional dos } \\
\text { arquivistas, bibliotecários e museólogos. }\end{array}$ \\
\hline Status técnico & $\begin{array}{l}\text { Associação absoluta das atividades arquivísticas a uma etapa preliminar do } \\
\text { trabalho historiográfico, em que a função do arquivista se resume a } \\
\text { organização dos documentos de modo que auxilie historiador. }\end{array}$ \\
\hline
\end{tabular}

Fonte: Dados da pesquisa.

Nas três formações discursivas é possível observar a função dos arquivos relacionada à cultura, entretanto, o projeto corporativo apresenta o domínio arquivístico com fronteiras mais amplas, perspectiva em que os arquivos "são essenciais ao desenvolvimento e a cultura" (ASSOCIAÇÃO DOS ARQUIVISTAS BRASILEIROS, 1972, p. 2). Desse ponto de vista, as questões arquivísticas atravessam os campos tanto da cultura quanto da administração, consequentemente, "valorizar os arquivos conseguindo-Ihes condições de bem cumprir sua dupla função, administrativa e cultural" (ASSOCIAÇÃO DOS ARQUIVISTAS BRASILEIROS, 1975a, p. 2).

Sobre o horizonte da Administração dentro do campo arquivístico, o discurso da Associação dos Arquivistas Brasileiros é de constatação da 
emergência do reconhecimento por parte das empresas de que seus arquivos seriam importantes recursos administrativos, o que está presente neste enunciado, "são muitas as empresas particulares que, organizadas dentro de padrões racionais, não se descuidam de seus arquivos" (ASSOCIAÇÃO DOS ARQUIVISTAS BRASILEIROS, 1972, p. 2). No projeto corporativo, "a formação universitária propiciará profissionais competentes para cuidar dos arquivos, tornando-se eficientes instrumentos da dinâmica empresarial ou administrativa" (ASSOCIAÇÃO DOS ARQUIVISTAS BRASILEIROS, 1973c, p. 5).

Na formação discursiva em que se inscreve o discurso da Associação de Pesquisa Histórica e Arquivística há uma ausência da perspectiva administrativa dos arquivos, é possível perceber uma ênfase exclusiva nas relações entre História e arquivos, estes como fundamentais para a pesquisa histórica, ao arquivista diz respeito somente a parte técnica, com um fazer auxiliar.

No próximo quadro, a coluna percentual foi estabelecida com base no universo de editoriais da revista da Arquivo \& Administração entre os anos de 1972 e 1978, que foram 19 edições, ou seja, o enunciado sobre as tensões entre arquivistas, historiadores, museólogos e bibliotecários esteve em $58 \%$ dos editoriais, foi o mais frequente, isso evidencia os contornos do ambiente de embates no qual a Associação dos Arquivistas Brasileiros propôs seu modelo de institucionalização do campo. O segundo enunciado mais frequente, em $47 \%$ dos editoriais, foi a participação do movimento associativo na criação da graduação em Arquivologia e da regulamentação da profissão de arquivista.

Tabela 1 - Enunciados da AAB nos editoriais da revista Arquivo \& Administração, 1972-1978

\begin{tabular}{l|c|c}
\hline \multicolumn{1}{c|}{ Enunciado } & Frequência & Percentual \\
\hline \hline $\begin{array}{l}\text { As relações entre arquivistas, historiadores, museólogos e bibliotecários } \\
\text { são conflituosas. }\end{array}$ & 11 & $58 \%$ \\
\hline $\begin{array}{l}\text { A regulamentação da profissão e a criação do Curso Superior em } \\
\text { Arquivologia são realizações da Associação dos Arquivistas Brasileiros }\end{array}$ & 9 & $47 \%$ \\
\hline Não há uma coordenação nacional dos arquivos brasileiros. & 7 & $37 \%$ \\
\hline Os arquivos envolvem questões culturais e de administração. & 5 & $26 \%$ \\
\hline A administração pública é negligente com seus arquivos. & 4 & $21 \%$ \\
\hline $\begin{array}{l}\text { O modelo da AAB para a institucionalização do campo arquivístico está } \\
\text { em sintonia com as propostas da Unesco. }\end{array}$ & 4 & $21 \%$ \\
\hline $\begin{array}{l}\text { O movimento associativo percebe-se como marco para a atividade } \\
\text { arquivística no país. }\end{array}$ & 4 & $16 \%$ \\
\hline $\begin{array}{l}\text { Universidades brasileiras tem interesse na criação da graduação em } \\
\text { arquivologia. }\end{array}$ & 3 & $11 \%$ \\
\hline A revista Arquivo \& Administração é um órgão de divulgação da área. & 2 & $11 \%$ \\
\hline $\begin{array}{l}\text { As empresas começaram a reconhecer a importância dos arquivos na sua } \\
\text { gestão. }\end{array}$ & 2 & $5 \%$ \\
\hline $\begin{array}{l}\text { A atuação do gênero feminino no associativismo arquivístico foi } \\
\text { determinante para suas realizações. }\end{array}$ & 1 & $5 \%$ \\
\hline Há conflitos na própria denominação da área. & 1 & $5 \%$ \\
\hline $\begin{array}{l}\text { Pessoas sem formação ou experiência atuam com os arquivos na } \\
\text { administração pública }\end{array}$ & 1 & 5 \\
\hline Fonte: Dados da pesquisa & & 5 \\
\hline
\end{tabular}

Fonte: Dados da pesquisa. 
O associativismo arquivístico representado pela AAB foi a instância de articulação e o dispositivo de ação que surge no início da década de 1970, e cujos indicadores de sua força são as realizações de metas de institucionalizar os sentidos dos termos Arquivologia e arquivista.

\section{Institucionalização acadêmico-universitária do saber arquivístico}

Em maio de 1971, no início do ano letivo do Curso Permanente de Arquivos que funcionava no Arquivo Nacional desde 1960, o diretor da instituição lamentava não poder oferecer o "reconhecimento dos certificados pelo Ministério da Educação e Cultura, nem uma perspectiva salarial atraente para a profissão" (ARQUIVO NACIONAL, 1971a, p. 5). Esse discurso caracteriza a realidade sobre a qual a Associação dos Arquivistas Brasileiros formulou seu projeto de institucionalização da área.

A situação merece uma reflexão. Até esse momento, o trabalho de arquivo é exercido no país por pessoas que adquiriram o saber arquivístico de maneira prática ou por intermédio de cursos técnicos como era o caso do que havia no Arquivo Nacional. A proposta de "levar a arquivologia à universidade" (ARQUIVO NACIONAL, 1971b, p. 4) é elevar, ao mesmo tempo, tanto o status do profissional que passaria ser de nível superior, quanto o reconhecimento acadêmico do saber arquivístico. Não foi uma decisão espontânea o modo como o saber arquivístico ingressou no ambiente acadêmico-universitário brasileiro, nos discursos é possível perceber o quanto esse percurso se confunde com a militância do associativismo da área.

No discurso da Associação dos Arquivistas Brasileiros a tradição brasileira em termos de pessoas a quem se atribui as atividades arquivísticas, na maior parte dos casos, seria de profissionais sem formação que "se arvoram em autoridades no assunto" (ASSOCIAÇÃO DOS ARQUIVISTAS BRASILEIROS, 1975a, p. 2). Em resposta, é projetada a institucionalização acadêmica do saber arquivístico por intermédio do curso superior de arquivo e esse foi o caminho feito quando se elaborou "o currículo mínimo do Curso Superior de Arquivologia, o qual, aprovado pelo Conselho Federal de Educação" (ASSOCIAÇÃO DOS ARQUIVISTAS BRASILEIROS, 1977b, p. 3), institucionaliza um sentido para Arquivologia no contexto brasileiro.

Nesse contexto o que mais chama a atenção é a questão de gênero, era um quadro sobre o qual se tinha a seguinte ideia: "bendito matriarcado que fortalece as esperanças da classe" (ASSOCIAÇÃO DOS ARQUIVISTAS BRASILEIROS, 1977a, p. 3). Em relação ao processo de submissão da proposta do curso superior de arquivo ao órgão responsável há também o discurso em que uma das participantes do coletivo se percebe protagonista. Astréa de Moraes e Castro publicou suas correspondências com o professor Vicente Sobriño Porto, a quem considera "nosso amigo e colega do meu marido", além de membro do Conselho Federal de Educação, e demonstra que foi a autora da "sugestão para que se crie o Curso de Arquivo, em nível superior" (CASTRO, 2008, 
p. 113) junto ao Conselho, valendo-se da relação de amizade para alcançar a aprovação.

Na busca pela criação do curso superior de arquivo, o que não estava estabilizado era a própria denominação da área. Nos editoriais da revista Arquivo \& Administração, entre 1972-1978, varia-se entre os termos Arquivologia (53\%) e Arquivística (47\%) para nomear essa área. É a partir dos documentos oficiais de aprovação do curso pelo Conselho Federal de Educação que a designação Arquivologia se torna a mais frequente e, posteriormente, a que se consagra na terminologia do campo no Brasil.

Em torno desse processo de institucionalização universitária do saber arquivístico no país, o desafio de justificar seu domínio acadêmico demandou a caracterização das relações com outras áreas, determinando uma produção discursiva em que pesou mais a demarcação das diferenças do que das interseções ou recobrimentos entre elas, essa postura pode ser observada, por exemplo, neste enunciado: "tendo alguns pontos de contato, têm também, pontos de divergência absoluta" (CASTRO, 2008, p. 115). Trata-se de uma tensão, às vezes, radicalizada: "museus não se confundem com arquivos" (ASSOCIAÇÃO DOS ARQUIVISTAS BRASILEIROS, 1974b, p. 5).

\section{Institucionalização da reserva de mercado do arquivista}

Em agosto de 1977, Marilena Leite Paz, então presidente da Associação dos Arquivistas Brasileiros, fez balanço das realizações desse movimento associativo:

Vencida a primeira e importante tarefa, qual seja, a de dotar o país de recursos humanos indispensáveis à salvaguarda e utilização de seu acervo documental, caberia a AAB pugnar pelo reconhecimento oficial da profissão. Em 1975, a AAB dirigiu-se ao Ministério do Trabalho para solicitar a Regulamentação da Profissão, recebendo daquele Ministério, e pessoalmente por parte do Senhor Ministro, demonstrações de sensibilidade para o problema e interesse pelo assunto. A matéria vem sendo estudada na esfera governamental e, já agora, no mês de agosto, será realizada uma reunião no Ministério do Trabalho (ASSOCIAÇÃO DOS ARQUIVISTAS BRASILEIROS, 1977b, p. 3).

O projeto da Associação dos Arquivistas Brasileiros foi instituir tanto a graduação na área como canal legítimo para formar arquivistas quanto a restrição legal do direito de exercício profissional aos egressos desse curso. Esse modelo institucionalizado pelo Estado brasileiro a partir de 1978 revogou uma situação jurídica vigente desde 1973, por intermédio do Decreto no 72.493, em que o trabalho arquivístico estava inserido na categoria funcional dos Técnicos em Assuntos Culturais, com formação em 
História ou Museologia. Na ocasião da promulgação de tal decreto, a reação do associativismo arquivístico tinha sido imediata, "desencanto para os profissionais de arquivo" (ASSOCIAÇÃO DOS ARQUIVISTAS BRASILEIROS, 1973b, p. 5).

Nesse caso é possível observar que havia uma alternativa de modelar a institucionalidade do trabalho arquivístisco de maneira contrária ao corporativismo que emergia por intermédio da Associação dos Arquivistas Brasileiros. Para Souza (2011, p. 58) "se os arquivistas revelevam alguma visibilidade ou representatividade, o qual era muito pouco provável, o Decreto anulou-as. Além de permitir a extinção do profissional arquivista, o Decreto favoreceu o exercício ilegal da profissão". Cinco anos depois houve tanto a revogação de tal disposição do Decreto no 72.493 quanto a regulamentação da profissão nos moldes desejados pelo associativismo arquivístico.

É importante observar que o projeto corporativo de regulamentação profissional do arquivista estava em contato com discursos discordantes. O historiador Rui Viera da Cunha, que atuou no setor de pesquisa histórica do Arquivo Nacional, apresentava um alerta sobre o que o projeto não deveria ser, alegando a compreensão reduzida do corporativismo de apenas fixar a reserva de mercado daqueles que trabalham vinculados ao problema de arquivo: "Não é um projeto visando a regular situações funcionais no Serviço Público. Não se trata de um aspecto de classificação de cargos ou de um problema vinculado a planos salariais" (ARQUIVO NACIONAL, 1975, p. 19).

O projeto corporativo de reserva de mercado que foi institucionalizado no campo arquivístico no Brasil na década de 1970 envolve desdobramentos atuais, são tensões que podem ser observadas na seguinte materialidade discursiva:

A exclusão dos profissionais não diplomados da categoria 'arquivista', por alguns segmentos brasileiros, representa um desejo pré-determinado [...] a exclusão de uma parte dos profissionais de arquivo com base em elementos formalistas, de cunho unicamente jurídico representa a defesa corporativa de supostos direitos de exercício profissional. A imensa maioria dos profissionais, responsáveis pela execução das atividades arquivísticas de dezenas de milhares de organizações públicas e privadas brasileiras, sequer têm sua existência reconhecida pelo viés 'legalista' (LOPEZ, 2012, p.189).

Na opinião de Lopez (2012) o corporativismo institucionalizado convive com uma realidade em que a maior parte dos profissionais que atuam com acervos arquivísticos hoje no Brasil não seria composta de egressos da graduação em Arquivologia. Na verdade esse autor questiona o modelo que foi instituído, propondo a sua revogação.

A expressão arquivista não foi a única denominação desse profissional no discurso da Associação dos Arquivistas Brasileiros, além 
dessa ele também foi designado pelos termos arquivologista e profissional de arquivo.

A definição das competências do arquivista foi algo instituído por intermédio da Lei 6.546, de quatro de julho de 1978 e regulamentada pelo Decreto 82.590, de seis de novembro de 1978, em que o exercício da profissão ficou restrita aos diplomados no Brasil por curso superior de Arquivologia, aos diplomados no exterior por cursos superiores de Arquivologia, cujos diplomas sejam revalidados no Brasil na forma da lei e aos que tivessem em 5 de julho de 1978 cinco anos ininterruptos de atividade ou dez intercalados, nos campos profissionais da Arquivologia.

Durante a década de 1970 o associativismo arquivístico realiza um trabalho de memória em seu discurso sobre o processo de institucionalização da área, em curso naquele período, que produz efeitos de glorificação própria. Desde o início do movimento se anuncia de modo triunfal demarcando que "a atividade arquivística encontra finalmente, em nosso país, o reconhecimento de sua importância" (ASSOCIAÇÃO DOS ARQUIVISTAS BRASILEIROS, 1972, p. 2), uma vez que foi organizada a Associação dos Arquivistas Brasileiros. Na medida em que se consegue reunir centenas de profissionais das diferentes regiões do Brasil no primeiro Congresso Brasileiro de Arquivologia, agora, "o movimento em prol da arquivística nacional vem tomando, a cada dia e por fim, um louvável e consciente impulso, irreversível no sentido de tratar com realismo e inteligência uma atividade" (ASSOCIAÇÃO DOS ARQUIVISTAS BRASILEIROS, 1973c, p. 5).

Nessa direção, apesar da agenda corporativa desse associativismo arquivístico, o discurso minimiza a centralidade do desejo de organizar a profissão de arquivista e opera no estatuto mais amplo do compromisso com o avanço na realidade arquivística, "a Associação dos Arquivistas Brasileiros desfraldou, desde a sua criação, em 1971, a bandeira da valorização dos Arquivos" (ASSOCIAÇÃO DOS ARQUIVISTAS BRASILEIROS, 1975b, p. 5) e "a partir da criação da AAB, em 1971, o panorama arquivístico brasileiro vem passando por transformações incontestáveis" (ASSOCIAÇÃO DOS ARQUIVISTAS BRASILEIROS, 1977b, p. 3). Houve momento em que o discurso tentou negar a realidade corporativa, como por exemplo, neste enunciado, "não deve ser confundida com uma associação de classe, buscando melhorias para um grupo profissional, mas se constitui em um ideal e uma força em prol do desenvolvimento material e intelectual do país" (ASSOCIAÇÃO DOS ARQUIVISTAS BRASILEIROS, 1975a, p. 2).

O discurso da Associação dos Arquivistas Brasileiros, desde a sua criação até a regulamentação da profissão em 1978, demonstra seus esforços para promover a profissão e, também, defender uma certa concepção do trabalho do arquivista. Nesse sentido apresenta uma diversidade nas funções do arquivista. 


\section{Considerações finais}

No discurso da Associação dos Arquivistas Brasileiros na década de 1970 podemos observar a organização de uma categoria profissional fora do sistema sindical, mas esse movimento está em relação com o Estado visando concretizar suas metas de institucionalização do campo arquivístico.

A convergência de esforços individuais configuraram uma rede no campo arquivístico que efetiva essa ação coletiva junto ao Estado, visando à institucionalização do espaço universitário da Arquivologia conjugado com a reserva de mercado do arquivista. O objetivo central da criação da Associação dos Arquivistas Brasileiros foi transformar a ocupação com os arquivos numa profissão institucionalizada e, portanto, foi um dispositivo evidente de ação coletiva para encaminhamento do projeto de institucionalização do campo arquivístico no Brasil. Desse movimento nasce a regulamentação do trabalho arquivístico no Brasil, inserido na excepcionalidade da situação de repressão política no país, mas sem que tais contextos e relações sejam explicitados em seus enunciados.

Esse projeto corporativo conviveu com concorrentes que acabaram sendo vencidos. As formações discursivas identificadas foram: a perspectiva bélica que o corporativismo assumiu na sua organização associativa; a compreensão integrada da formação e do exercício profissional dos arquivistas, bibliotecários e museólogos, proposta pelo DASP; e, o entendimento absoluto das atividades arquivísticas a uma etapa preliminar do trabalho historiográfico, em que a função do arquivista se resume à organização dos documentos de modo que auxilie o historiador, defendida pela Associação de Pesquisa Histórica e Arquivística.

A busca pela institucionalização desse modelo corporativo está presente no discurso da Associação dos Arquivistas Brasileiros, materializado nos editoriais de seu periódico, a revista Arquivo \& Administração, entre 1972 e 1978. Ao tomarmos tal materialidade discursiva, com o objetivo de compreender a relação entre o associativismo arquivístivo e a institucionalização desse campo, é evidente também que se trata de uma produção discursiva na qual se opera uma construção de memória sobre o processo de institucionalização do campo arquivístico.

Como devemos interpretar os fatores contribuíram para o êxito do associativismo arquivístico? Depois de uma década de incessantes esforços para eliminar do campo profissional o livre exercício da ocupação, para elevar o nível da formação, uma rede de pessoas interessadas nos arquivos, em condições históricas de restrição política, construiu articulações frente ao Estado, diante de pontos de vista contrários, se tornando um movimento associativo realizador em suas demandas. A institucionalização do campo arquivístico no Brasil foi uma realização - e também o esgotamento da agenda - do associativismo instituído através da Associação dos Arquivistas Brasileiros, em 1971, configurando o 
processo histórico que caracteriza os vigentes sentidos em disputa para arquivo (objeto), arquivologia (saber) e arquivista (especialista).

\section{Referências}

ARQUIVO NACIONAL. Mensário do Arquivo Nacional, Rio de Janeiro, ano 2, n. 5, maio 1971a.

ARQUIVO NACIONAL. Mensário do Arquivo Nacional, Rio de Janeiro, ano 2, n. 9 , set. $1971 \mathrm{~b}$.

ARQUIVO NACIONAL. Mensário do Arquivo Nacional, Rio de Janeiro, ano 6, n. 8, ago. 1975.

ASSOCIAÇÃO DOS ARQUIVISTAS BRASILEIROS. Arquivo \& Administração, Rio de Janeiro, v. 1, n. 0, 15/20 out. 1972. (10 Congresso Brasileiro de Arquivologia)

ASSOCIAÇÃO DOS ARQUIVISTAS BRASILEIROS. Arquivo \& Administração, Rio de Janeiro, v. 1, n. 1, abr., $1973 a$.

ASSOCIAÇÃO DOS ARQUIVISTAS BRASILEIROS. Arquivo \& Administração, Rio de Janeiro, v. 1, n. 2, set., 1973b.

ASSOCIAÇÃO DOS ARQUIVISTAS BRASILEIROS. Arquivo \& Administração, Rio de Janeiro, v. 1, n. 3, dez., 1973c.

ASSOCIAÇÃO DOS ARQUIVISTAS BRASILEIROS. Arquivo \& Administração, Rio de Janeiro, v. 2, n. 1, abr., 1974 a.

ASSOCIAÇÃO DOS ARQUIVISTAS BRASILEIROS. Arquivo \& Administração, Rio de Janeiro, v. 2, n. 2, ago., 1974b.

ASSOCIAÇÃO DOS ARQUIVISTAS BRASILEIROS. Arquivo \& Administração, Rio de Janeiro, v. 2, n. 3, dez., 1974C.

ASSOCIAÇÃO DOS ARQUIVISTAS BRASILEIROS. Arquivo \& Administração, Rio de Janeiro, v. 3, n. 1, abr., 1975a.

ASSOCIAÇÃO DOS ARQUIVISTAS BRASILEIROS. Arquivo \& Administração, Rio de Janeiro, v. 3, n. 2, ago., 1975b.

ASSOCIAÇÃO DOS ARQUIVISTAS BRASILEIROS. Arquivo \& Administração, Rio de Janeiro, v. 3, n. 3, dez., 1975c.

ASSOCIAÇÃO DOS ARQUIVISTAS BRASILEIROS. Arquivo \& Administração, Rio de Janeiro, v. 4, n. 1, abr., 1976 a.

ASSOCIAÇÃO DOS ARQUIVISTAS BRASILEIROS. Arquivo \& Administração, Rio de Janeiro, v. 5, n. 2, ago., 1976b.

ASSOCIAÇÃO DOS ARQUIVISTAS BRASILEIROS. Arquivo \& Administração, Rio de Janeiro, v. 4, n. 3, dez., 1976c.

ASSOCIAÇÃO DOS ARQUIVISTAS BRASILEIROS. Arquivo \& Administração, Rio de Janeiro, v. 5, n. 1, abr., 1977a. 
ASSOCIAÇÃO DOS ARQUIVISTAS BRASILEIROS. Arquivo \& Administração, Rio de Janeiro, v. 5, n. 2, ago., 1977b.

ASSOCIAÇÃO DOS ARQUIVISTAS BRASILEIROS. Arquivo \& Administração, Rio de Janeiro, v. 5, n. 3, dez., 1977c.

ASSOCIAÇÃO DOS ARQUIVISTAS BRASILEIROS. Arquivo \& Administração, Rio de Janeiro, v. 6, n. 1, abr., 1978a.

ASSOCIAÇÃO DOS ARQUIVISTAS BRASILEIROS. Arquivo \& Administração, Rio de Janeiro, v. 6, n. 2, ago., 1978b.

ASSOCIAÇÃO DOS ARQUIVISTAS BRASILEIROS. Arquivo \& Administração, Rio de Janeiro, v. 6, n. 3, dez., 1978c.

CASTRO, A. de M. e. Arquivologia: sua trajetória no Brasil. Brasília, DF: Stilo, 2008.

CRESPO, C. D. O campo da arquivística e os arquivos setoriais: conhecimentos e práticas. 2000. Dissertação (Mestrado em Comunicação, Imagem e Informação) - IACS, Universidade Federal Fluminense, Niterói, 2000.

FERNANDES, C. A. Análise do discurso: reflexões introdutórias. São Carlos, SP: Claraluz, 2008.

FONSECA, M. O. Arquivologia e Ciência da Informação: (Re) definição de marcos interdisciplinares. 2004. Tese (Doutorado em Ciência da Informação) - IBICT, Escola de Comunicação, Universidade Federal do Rio de Janeiro, Rio de Janeiro, 2004.

FOUCAULT, M. A arqueologia do saber. São Paulo: Forense Universitária, 2005.

GOMES, Y. Q. Processos de institucionalização do campo arquivístico no Brasil (1971-1978): entre a memória e a história. 2011. Dissertação (Mestrado em Memória Social) - Universidade Federal do Estado do Rio de Janeiro, Rio de Janeiro, 2011

ORLANDI, E. de L. P.; GUIMARÃES, E. R. J. O conhecimento sobre a linguagem. In: PFEIFFER, C. C.; NUNES, J. H. (Org.). Introdução às ciências da linguagem: linguagem, história e conhecimento. Campinas-SP: Pontes Editores, 2006. v. 2. p. 141-157.

LOPEZ, A. P. A. A formação de arquivistas no Brasil: notas para um debate. In: VALENTIM, M. L. P. (Org.). Estudos avançados em Arquivologia. Marília: Oficina Universitária; São Paulo: Cultura Acadêmica, 2012.

MAIA, A. M. A construção do Curso de Arquivologia da UNIRIO: dos primeiros passos à maturidade universitária. 2006. Dissertação (Mestrado em Pedagogia) - Centro de Ciências Humanas e Sociais, Universidade Federal do Estado do Rio de Janeiro, Rio de Janeiro, 2006.

MARQUES, A. A. da C. Os espaços e os diálogos da formação e configuração da arquivística como disciplina no Brasil. 2007. Dissertação 
(Mestrado em Ciência da Informação) - Departamento de Ciência da Informação, Universidade de Brasília, Brasília, 2007.

MARQUES, A. A. da C. Interlocuções entre a Arquivologia nacional e a internacional no delineamento da disciplina no Brasil. 2011. Tese (Doutorado em Ciência da Informação) - Faculdade de Ciência da Informação da Universidade de Brasília (UnB), Brasília, 2011.

RICOUER, P. A memória, a história, o esquecimento. Campinas: Ed. Unicamp, 2007.

SANTOS, P. R. E. dos. A arquivística no laboratório: história, teoria e métodos de uma disciplina. 2008. Tese (Doutorado em História) Faculdade de Filosofia, Letras e Ciências Humanas, Universidade de São Paulo, São Paulo, 2008.

SILVA, M. L. R. da. História e memória do Arquivo Central da FGV. 2010. Dissertação (Mestrado em Bens Culturais e Projetos Sociais) - Centro de Pesquisa e Documentação de História Contemporânea do Brasil (CPDOC), Rio de Janeiro, 2010.

SILVA, E. P.; ORRICO, E. G. D. Associação de Arquivistas no Brasil na década de 1970. Revista Ibero-Americana de Ciência da Informação, v. 5, p. 93-109, 2012.

SOUZA, K. I. M. de. Arquivista, visibilidade profissional: formação, associativismo e mercado de trabalho. Brasília: Starprint, 2011. 